\title{
Exploring Challenges Faced By Small Business Owners on Poverty Reduction in Rural Eastern Cape, South Africa
}

\author{
O.P.Akinwale ${ }^{1}$, E. Adu ${ }^{2}$, I. Seriki ${ }^{3}$ \\ ${ }^{1}$ Department of Development Studies, University of Fort Hare, Alice 5700, Eastern Cape, South Africa \\ ${ }^{2}$ Department of Education, University of Fort Hare, P. O. Box 7426, East London Campus, South Africa. \\ ${ }^{3}$ Department of Public administration, University of Fort Hare, Alice 5700
}

\begin{abstract}
Small Business can serve as a tool for poverty reduction in South Africa, but it requires adequate support and development for its continuous sustenance in spite of rigorous challenges, especially in the rural environment. This study explored the challenges faced by the small business owners in the rural Eastern Cape Province of South Africa. The objective of the study is to identify the challenges faced by small business owners in the case study area and to examine the effects of those challenges on poverty rate. Survey research design was adopted, with the distribution of structured questionnaire for data collection through a simple random sampling method. Descriptive and inferential statistics was used to analyze the data. Findings showed that small business owners face various challenges in their commercial operations. It was also made clearer that these challenges have effects on the poverty rate as well as crime rate. In conclusion, in other for small businesses to be affective instrument to tackle poverty, certain measure must be taken into considerations. This therefore necessitates recommendation from the researcher that potential and current business owners must seek valuable advice from the more experienced business tycoon and seek information about the business assistance programmes provided by government and private sectors.
\end{abstract}

Keywords: Eastern Cape, Poverty, Poverty Reduction, Rural, Small Business, Sustainable Livelihood

\section{INTRODUCTION}

With in the developed and developing countries of the world, it is now generally accepted by policy-makers at local, regional and national level, that small- medium sized enterprises are becoming increasingly important in terms of poverty reduction, employment, wealth creation and the development of innovation (Shafeek 2006:2), rural areas in developing worlds also are part of this embracement. Accordingly, South African rural areas are important because over $75 \%$ of the population reside and derive their livelihoods there, while approximately $70 \%$ of these rural people are poor (Statistics South Africa 2012:3) because of the inability of their rural economies to provide them with remunerative jobs or self-employment opportunities.

Rural areas are known to be most isolated and remote areas due to the nature of the infrastructure. These rural areas contribute less to the economy of the country and their low contribution remains a cause of concern. On the other hand, small businesses contribute significantly to the nation's development and to local economies. More employment opportunities have been created through business worldwide. For example, in 2008 and 2009, small businesses have created job opportunities for a larger number of employees in Nigeria's rural areas increasing the economic growth of the country by $80 \%$ (Aliyu \& Bello 2013).

Eight percent of work force in rural Eastern Cape is employed under formal sector, twenty-eight percent is unemployed while sixty-four percent of working age is economic active (Amathole Economic Development Agency, 2010:2). The need to eradicate poverty through small business innovation therefore arises. Although, majority of these rural dwellers engage in small business yet high rate of poverty still persists in Eastern Cape which makes it the second poorest province in South Africa (National Development Agency 2014:50).

\section{Problem Statement}

Major problem identified in this study is that small business in Eastern Cape continues to fail in its efforts to reduce poverty. High rate of poverty in the rural Eastern Cape continue therefore continue to grow. Eastern Cape has recorded the huge figure of unemployment rate to the tune of 30.8\% among other provinces in South Africa which is

${ }^{1}$ Corresponding Author: soladayo123415@yahoo.com 


\section{American Research Journal of Humanities and Social Sciences, Volume 1, Issue 2, April 2015}

ISSN 2378-7031

actually the root of the high rate of poverty in the province, and thereby resulted to high crime rate, adolescence prostitution, armed robbery and other social vices (Statistics South Africa 2013:11). Therefore, the main purpose of this study is to explore those challenges face by small businesses in their effort to reduce poverty.

\section{RESEARCH QUESTIONS}

$>$ Are there any challenges faced by the small business owners?

$>$ What are the challenges faced by the small business owners?

What are the effects of those challenges on poverty rate reduction?

\section{SUSTAINABLE LIVELIHOOD THEORY}

According to (Krantz 2001:6) The sustainable livelihoods idea was first introduced by the Brundtland Commission on Environment and Development as a way of linking socioeconomic and ecological considerations in a cohesive, policy-relevant structure. It was expanded in 1992 by United Nations Conference on Environment and Development.

A livelihood comprises the capabilities, assets (stores, resources, claims and access) and activities required for a means of living: a livelihood is sustainable which can cope with and recover from stress and shocks, maintain or enhance its capabilities and assets, and provide sustainable livelihood opportunities for the next generation; and which contributes net benefits to other livelihoods at the local and global levels and in the short and long term (Krantz 2001:6). This means, a livelihood implies that indicators of wellbeing are subjective.

The IDS framework of 1998 on sustainable livelihood for poverty reduction accords the efforts of both Sen (1984; 1987), and Chambers (1995) respectively. Sen refers to capabilities as a concept that is far beyond having more than material things and food but what people can do or acquire with their income. Five major indications for sustainable livelihoods were highlighted in IDS framework: creation of working days; poverty reduction; well-being and capabilities; livelihood adaptation, vulnerability and reliance and; natural resources. Therefore, Poverty reduction is the major evaluation of livelihood indicating that when capability is guaranteed, the level of poverty will be reduced in the society.

The most valuable means to empower people is to broaden the range of strategy alternatives through diversification into livelihood options that actually minimizes vulnerability (Goldman 2000). The process of poverty reduction entails social policy measures in which people's wellbeing are positively affected. This can be through welfare services or by the implementation of good policies that can have optimistic impact on lives.

One of the strength of the sustainable livelihood Approach is that creates a complete view on how resources or combination of resources are important to the poor, including not only physical and natural resources, but also their social and human capital. Secondly, sustainable livelihood promotes the knowledge to identify the reasons behind poverty by concentrating on the various factors at different levels that determines poor people's access to resources/assets of different kinds, as well as their livelihoods. Lastly, sustainable livelihood approach provides an accurate plan and channels to assess the direct and indirect effects on people's living conditions than, one dimensional productivity or income criteria.

On the other hand, sustainable livelihood has some weaknesses. According to Krantz (2001:4), none of the sustainable livelihood approaches really deal with the issue of how to identify the poor themselves. In the context of sustainable livelihood, resources and other livelihood opportunities are distributed locally and influenced by informal structures of social dominance and power within the communities themselves.

The basic idea of the sustainable livelihood approach is to start with a broad and open-ended analysis, but this requires a highly flexible planning situation which rarely exists. So, the best hope is to ensure that already identified/decided sector development initiatives fit with people's livelihood strategies and make them better at responding to the constraints and opportunities affecting the poor. Thus, the approach, or its elements, will useful to that end (Krantz 2001:5).

\section{SMall Business Policy in South Africa}

According to Rhoman (2006) in National Small Business Act 1996 small business means any entity, whether or not incorporated or registered under any law, which consists mainly of persons carrying on small business concerns in any economic sector, or which has been established for the purpose of promoting the interests of or representing small business concerns. 
The World Bank defined small business as a business having up to 300 employees; the European Union defined it as having up to 200 employees (OECD 2004:7) Although, both institutions described small business in a different way, but the important thing is that small business are entities with small employees. In some developed countries, enterprises with or fewer than 500 employees are usually considered small and medium enterprises, while the case is different in developing countries.

In South Africa, enterprises with five or less employees, whose annual turnover is below the compulsory VAT registration limit, are occasionally described as small businesses (Department of trade and Industry, 2007:2). And such small businesses are the focus of this study.

Based on opening domestic markets to the world, many countries have endeavored to promote small business sectors and equip local firms against challenges. South Africa's small business policy is principally informed by the 1995 "Whitepaper on national strategy on the development and promotion of small business in South Africa" (Timm, 2011:20). The country has also developed institutions and agencies to support small businesses, with access to financial and business support. According to (Timm, 2011), South Africa's 1995 White Paper outlined among other things the need for the government to create an enabling legal framework, facilitate access to information and advice, boost procurement from small firms and to improve access to finance and affordable physical infrastructure. The policy also led to the 1996 National Small Business Act as well as the launching of Khula enterprise Finance Limited in the same year, to dispense both financial non-financial supports.

Despite various initiative over the 17 years aimed at both high end enterprise development and the reassurance of small enterprises, government support agencies and initiatives have less impact than intended (Timm 2011). Therefore, importance of funding and support initiatives towards the growth of small business has not yield the desired effect in growing the small firm sectors.

\section{Poverty in Eastern Cape}

According to Rogan (2012), poverty is attributed to lack of ability to control a suitable strategy in the time of crisis. Individuals and households poverty is therefore result to lack of amenities that obstruct them to manage negative effects of external shock. Poverty is also a state of material and social deprivation that make individuals go below the social acceptable standard of living that make them to experience social deprivation in the society. And this the kind of poverty experienced by the people in rural Eastern Cape.

With a percentage rank of 35.7\%, Eastern Cape is the second poorest province in South Africa (Statistics South Africa 2012:11). Westway (2012) stressed that, 73\% of the rural people in the Eastern Cape lives on less than R300 per month in 2005/06, while more than half of them build their survival on less than R220 per month. The average rural income including was R255 per month, which is well below the poverty line of R293 per month drawn by the Presidency in 2008 (Westaway 2012). Amathole Economic Development Agency (2010:2); highlights that more than $50 \%$ of the formal jobs that exists rural Eastern Cape are provided by education sector Thus, in order to deal with the pressure of unemployment crisis the majority of the rural dwellers ventures into small business in which the majority of owners are women, because it is easier for women to swallow their pride when poverty strikes (Narayan et al. 2000). According to Holmes (2001) Small businesses in the rural areas are ways in which centralizing forces in the distribution of power in the society can be counterbalanced.

\section{VII.POVERTY REDUCTION VERSUS SMALL BUSINESS}

The South African's small business sector has been neglected much century back following the discovery of diamonds and gold and the establishment of a modern, capitalist economy with almost exclusive control (Ministry of Trade and Industry 1994:9). However, the South African government has since identified the small business sector as a priority in creating jobs to solve the high unemployment condition. The small business sector has a major role to play in the South African economy in terms of employment creation and income generation. Small businesses accounts for approximately $60 \%$ of all employment in the economy and more than $35 \%$ of South Africa's GDP (Ntsika 2002:110). It is the vehicle by which the lowest income people in the society gain access to economic opportunities at a time that distribution of income and wealth in South Africa is amongst the most unequal in the world.

Rural areas are more exposed to poverty as compared to urban areas. The rural-urban distance, in both intensity and incidence of poverty, has in general not shrunk in the 1980s and 1990s (Lipton 1999:10). Rural poverty is continuing to show higher incidence, and almost certainly to affect many people globally. Even though small businesses keeping offers a promising to fight poverty in many developing countries by creating employment, small business owners need access to loans for their initial capital. 


\section{American Research Journal of Humanities and Social Sciences, Volume 1, Issue 2, April 2015}

ISSN 2378-7031

Vadenberg in International Labor Organization (2006) focuses on how to bring the poor people into the small enterprises economy through small business. The approach is placed on four essential pillars of decent work which are; productive and remunerative employment; rights at work; social dialogue and social security. (Vadenberg 2006:8) explained the similarities between small enterprises as decent works and poverty reduction that; both of them emphasize that people's welfare is based on the income they realized from a very productive employment and social security.

Right at work, has to do with the right of an individual to associate and bargain, freedom from gender and racial discrimination as well as a safe and healthy work environment. If individual are free from the fear of illegal seizure of property by public officials, it will be a motivation for them to venture in small business. The second pillar in ILO framework is productive and remunerative employment, which emphasized that investments that are made on the productive enterprises can generate sufficient income for the business owners and the success of poverty reduction is thereby guaranteed. If success is made in small business and productivity is achieved, then sustainable livelihood will be equally assured. The third pillar supports the provision of social security to the people either by public or private forms. This will strengthen and improve wellbeing of the poor. Lastly, the fourth pillar suggests that there must be social dialogue, which will enable small business to gain more momentum to small business.

\section{METHODOLOGY}

The study adopted descriptive survey research design to investigate challenges faced by small business owners on poverty reduction in Eastern Cape South Africa.

\section{A. Research design}

The study adopted descriptive survey research design to investigate challenges faced by small business owners on poverty reduction in Eastern Cape South Africa.

\section{B. Population/Sample}

The study covers small business owners/operators of thirty populations of which twenty-four sample size were selected in retailing and wholesaling businesses. Majority of these businesses contributes greatly to the economy of the Eastern Cape.

\section{Validity and Reliability of Research Instrument}

Data was attained through the use of structured questionnaire. The instrument was validated by the experts in the same field of entrepreneurship and Cronbach alpha was used to measure its reliability because it can be used as the predictable correlation of two tests that measure the same construct. The reliability coefficient is $r=0.74$.

\section{D.Data Administration and Analyses}

A research assistant assisted the researcher in administering the instrument; data were collected and analyzed using descriptive and inferential statistics of Chi-Square statistics.

\section{RESULTS AND DISCUSSION}

\subsection{Level of Response}

A total number of twenty-five questionnaires was distributed to small business owners, 22 was recovered while two questionnaires were not returned as shown in table 1 below.

Table I. Units for Magnetic Properties

\begin{tabular}{|l|l|l|}
\hline No. of questionnaires distributed & No. of questionnaires returned & Level of response \\
\hline 24 & 22 & $92 \%$ \\
\hline
\end{tabular}

\subsection{Demographic Information}

The demographic information in this study identified and discusses demographic factors that are mostly in relation to gender and age of the business owners in the rural Eastern Cape. Necessary questions such as age of respondent and educational background of respondent were asked.

\subsection{Age Distribution}

The question of real age of the respondents is a personal affair and most of them may not feel comfortable to state their real age, so the age range used is between sixty in a group form. 


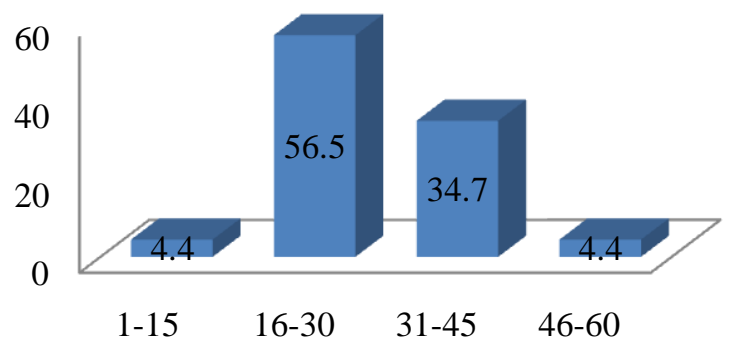

- Age group distribution

Fig1. Age group distribution

As shown in figure 1 above, $4.4 \%$ fall below the age of sixteen, $34.7 \%$ within ages sixteen to $30,56.5 \%$ between ages thirty-one and 45 while $4.4 \%$ is above forty-five years. The highest age group in the above chat is within 16 and 45 which means majority of work force in rural Eastern Cape are unemployed, this is in relation to the notion of Amathole Economic Development Agency (2010:2) which highlighted that a larger population of work force in rural Eastern Cape are not able to secure jobs in the formal sector.

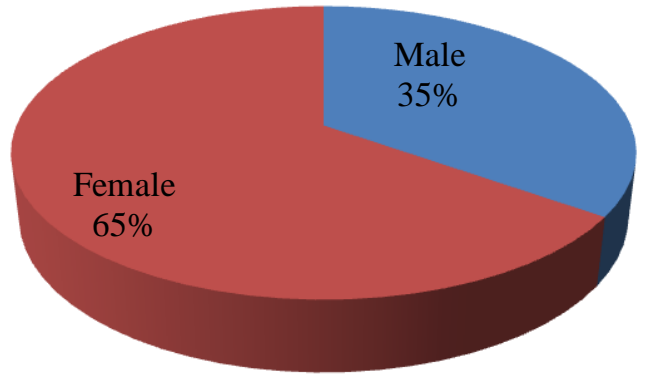

Fig2. Gender of respondents

Figure 2 above indicate that $65 \%$ of female engage in small business operations, while $35 \%$ speaks for male in small business ventures. Therefore the above results prove right the argument of Narayan et al (2000) that when hunger strikes, it is easier for women to swallow their pride than men. This means women are adaptive to engage in various occupations to earn for survival.

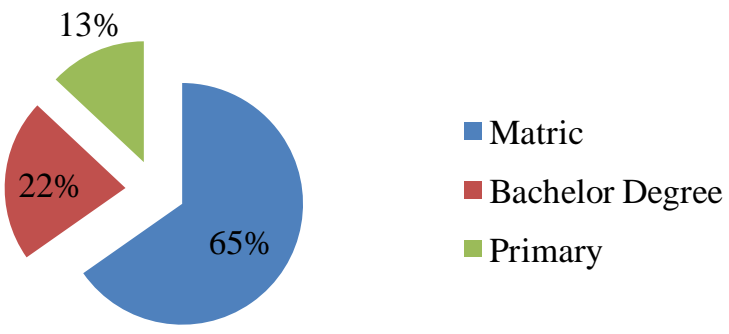

Fig3. Level of education

The level of education obtained by respondents is important to determine if those business owners are even educated at all. As illustrated in figure 3 above, majority of the respondents are educated, only $13 \%$ of the respondents are not educated. 
American Research Journal of Humanities and Social Sciences, Volume 1, Issue 2, April 2015 ISSN 2378-7031

Research question 1: Are there any challenges faced by the small business owners?

Table2. Small business challenges

\begin{tabular}{|l|l|l|l|l|l|}
\hline & Strongly agreed & Agreed & Undecided & Disagreed & Strongly disagreed \\
\hline $\begin{array}{l}\text { Challenges faced by small } \\
\text { business owners are numerous }\end{array}$ & 52.0 & 45.0 & 3.0 & 0 & 0 \\
\hline
\end{tabular}

In table 2 above, data shows that truly small business owners face challenges as $52 \%$ of the respondents strongly agreed and $45 \%$ agreed while only $3 \%$ refused to decide.

Research Question 2: What are the challenges faced by the small business owners?

Table3. Various challenges of small business

\begin{tabular}{|l|l|l|l|l|l|}
\hline & Strongly agree & Agreed & Undecided & Disagree & Strongly disagree \\
\hline Asess to capital & 50.0 & 33.6 & 11.4 & 3.2 & 1.8 \\
\hline Lack of knowledge and skills & 48.0 & 34.8 & 8.7 & 4.2 & 4.3 \\
\hline Poor marketing & 52.3 & 34.9 & 9.2 & 0 & 3.6 \\
\hline Lack of direction and planning & 67.2 & 28.6 & 4.2 & 0 & 0 \\
\hline Lack of Innovation & 43.5 & 32.5 & 13.8 & 6.7 & 3.5 \\
\hline
\end{tabular}

From the above results, it can be said that small business owners faces various challenges that has abridged their capacity to reduce poverty to reasonable level. As reflected above, 50\% of respondents strongly agreed, $33.6 \%$ agreed, $1.8 \%$ strongly disagreed, $3.2 \%$ who disagreed and $11.4 \%$ who were undecided.

Research Question 3: What are the effects of those challenges on poverty rate reduction?

\begin{tabular}{|l|l|l|l|l|l|}
\hline & Strongly agree & Agreed & Undecided & Disagreed & Strongly disagreed \\
\hline Increase in unemployment rate & 74.8 & 7.3 & 4.7 & 10.8 & 2.4 \\
\hline Increase in crime rate & 42.1 & 15.9 & 5.1 & 24.1 & 12.8 \\
\hline Adolescence prostitution & 18.4 & 17.3 & 2.6 & 49.3 & 12.4 \\
\hline Armed robbery & 65.4 & 20.8 & 3.4 & 6.1 & 4.3 \\
\hline High increase in disease and death rate & 59.3 & 35.2 & 0 & 2.9 & 2.6 \\
\hline
\end{tabular}

The result obtained from effects of small business challenges on poverty is that $74.8 \%$ strongly agreed and $7.3 \%$ agreed, as compared to $2.4 \%$ who strongly disagreed, $10.8 \%$ disagree and $4.7 \%$ are undecided that challenges of small business is a reflection of high rate of poverty.

\section{CONClusion}

This study has explored on the numerous challenges faced by small business owners in poverty reduction. The efforts to reduced poverty line in their environment has become a tough task for them as they battle with financial difficulties, skill development, poor marketing among other challenges. The literature revealed that the South African's small business sector has been neglected much century back following the discovery of diamonds and gold and the establishment of a modern capitalist economy with almost exclusive control.

\section{RECOMMENDATIONS}

The empirical results and literature plainly showed that venturing into small business is an effective tool to create employment for the unemployed and thereby reduce the poverty rate in society. However, majority of the owners faces huge challenges; small business owners should adequately enquire about likely challenges while intending to go into business, learning from the experienced and successful business colleagues may really help them. Meanwhile potential business owners can consult government agencies and private entities that have financial assistance programmes to assist small businesses rather than relying on their own little saving that may not be adequate to flourish the business. At this stage, it is important for both potential and existing business owners to be aware of the business development assistance that are available in their region, the results therefore suggest this aspect as an area for further research.

\section{REFERENCES}

[1] Aliyu, S 2013. An Assessment of the Contribution of Commercial Bank tothe Growth of Small and Medium Scale Enterprises in Nigeria. International Journal of Research in Social Sciences, 2(4) pp. 47-55. 


\section{American Research Journal of Humanities and Social Sciences, Volume 1, Issue 2, April 2015 ISSN 2378-7031}

[2] Chambers, R 1995. Poverty and Livelihoods: Whose Reality Counts? Environment and Urbanization, 7(1), pp 173-204.

[3] Amathole Economic Development Agency 2010. Alice Regeneration programme: High level feasibility assessment report. ASPIRE. East London.

[4] Department of Trade and Industry 2007.Integrated Strategy on the Promotion of Entrepreneurship and Small Enterprise in South Africa: DTI, South Africa.

[5] International LaborOrganization ILO 2004.The challenges of Growing Small Businesses: Insights from Women Entrepreneurs in Africa. Richardson. Geneva: International Labor Office.

[6] Krantz, L 2001.The Sustainable Livelihood Approach to Poverty Reduction, an Introduction: Swedish International Development Cooperation Agency.

[7] Lipton M 1999. Reviving Global Poverty Reduction: What Role for Genetically Modified Plants? CGIAR International Centers: Washington.

[8] Ministry of Trade and Industry 1994.Strategies for the development of an integrated policy and support program for Small, Medium and Micro enterprises in South Africa: South African Government.

[9] Narayan, D et al 2000. Voices of the Poor: Can Anyone Hear Us? USA: Oxford University Press.

[10] National Development Agency 2014.The State of Poverty and Its Manifestation in the Nine Provinces of South Africa: Report Outline. South Africa, HSRC.

[11] Ntsika, 2002. State of Small Business in South Africa: Annual Review. Pretoria: Ntsika Enterprise Promotion Agency.

[12] OECD 2004.Promoting Entrepreneurship and Innovative SMEs in A Global Economy: Towards a more Reasonable and Inclusive Globalization. Istanbul, Turkey.

[13] Rhoman 2006. National Small Business Act 1996, No. 102. South African Government.

[14] Rodgan, M 2012. Poverty and Headship in Post-apartheid South Africa. Economic Research South Africa, (ERSA).

[15] Scott, H 2001. Definition of Small Business -- Final Report on Small Business in Australia, April 5, 2001. Callaghan: University of New Castle.

[16] Sen, A 1984. Resources, Values and Development, Oxford: Basil Blackwell

[17] Shafeek, S. 2006. An Investigation into Problems Facing Small-to-Medium Sized Enterprises in Achieving Growth in the Eastern Cape. Rhodes University. South Africa.

[18] Statistics South Africa 2012. Quarterly labor force survey. Quarter 3. Pretoria.

[19] Vadenberg, P 2006. Poverty Reduction through Small Enterprises. International Labor (ILO): Geneva.

[20] Westway, A 2012. Rural Poverty in the Eastern Cape Province: Legacy of Apartheid or Consequence of Contemporary Segregationism? Development of South African Journal, 29:1,115-125. 